DOI: 10.20472/IAC.2018.038.043

\title{
LALIDA WIBOONWACHARA
}

Chiang Mai Rajabhat University, Thailand

\section{ENHANCING CRITICAL THINKING OF THAI EFL LEARNERS THROUGH QUESTIONING TECHNIQUE}

\begin{abstract}
:
Nowadays, many Thai educators consider using more effective techniques to teach and to foster critical thinking in the classroom. Critical thinking is one of the most vital skills that learners should develop in order to survive in the real world. Critical thinking can help learners analyze, judge and evaluate massive amount of information in daily life, and prevents them from being trapped in biases and accepting incorrect information. Moreover, critical thinking can help construct their knowledge more effectively. Learners should be able to assess their thinking carefully in order to shape their thinking process. Questioning is one way to help them think critically. This classroom research aimed to enhance students' critical thinking through question - based activities in EFL classroom, and to examine the opinions and awareness of students towards question - based activities. The sample consisted of 43 second-year English major students. The research instruments were 1) question-based lesson plans of an Inferential Reading course 2) 25 questions with 5 multiple choices to assess their critical thinking skills 3 ) a five-scale opinion questionnaire used to explore the students' opinion on English language instruction through questioning technique in the Inferential Reading course and 4) students' reflective writing on the instruction in the Inferential Reading course. The results showed that the students' critical thinking skills were higher after participating in the question-based activities at 0.01 level of significance, and the students' opinions towards question-based activities was at a high level $(=4.49)$. The students were aware of the importance and benefits of questioning both in academic sense and in everyday life situations. Moreover, they realized that asking questions could help improve their critical thinking skills. They learned how to carefully consider the information before making any decisions.
\end{abstract}

\section{Keywords:}

Questioning, Critical Thinking, EFL learners 